\title{
Por dentro do Hospital Colônia Santana: uma leitura etnográfica de prontuários psiquiátricos de mulheres internas nas décadas de 1940 e 1950
}

Inside the Colonia Santana Hospital: an ethnographic reading of psychiatric records of women internees in the 1940s and 1950s

Sônia Weidner Maluf, Mirella Alves de Britto, Inaê label Barbosa e Camila Andressa Dias da Silva

\section{(2) OpenEdition Journals}

Edição electrónica

URL: http://journals.openedition.org/aa/5799

DOI: 10.4000/aa.5799

ISSN: 2357-738X

Editora

Programa de Pós-Graduação em Antropologia Social (UnB)

Edição impressa

Paginação: $54-75$

ISSN: 0102-4302

Refêrencia eletrónica

Sônia Weidner Maluf, Mirella Alves de Britto, Inaê label Barbosa e Camila Andressa Dias da Silva, «Por dentro do Hospital Colônia Santana: uma leitura etnográfica de prontuários psiquiátricos de mulheres internas nas décadas de 1940 e 1950», Anuário Antropológico [Online], v.45 n.2 | 2020, posto online no dia 27 maio 2020, consultado o 27 abril 2021. URL: http://journals.openedition.org/aa/5799 ; DOI: https://doi.org/10.4000/aa.5799

\section{(c) $(9)$}

Anuário Antropológico is licensed under a Creative Commons Atribuição-Uso Não-Comercial-Proibição de realização de Obras Derivadas 4.0 International. 


\title{
anuário antropológico
}

v. $45 \cdot n \cdot 2$ - maio-agosto $\cdot 202 \odot .2$

\section{Por dentro do Hospital Colônia Santana: uma leitura etnográfica de prontuários psiquiátricos de mulheres internas nas décadas de 1940 e 1950}

\author{
Inside the Colonia Santana Hospital: an ethnographic reading of \\ psychiatric records of women internees in the 1940s and 1950s
}

DOI: https://doi.org/10.4000/aa.5799

\begin{abstract}
Sônia Weidner Maluf • Universidade Federal de Santa Catarina - Brasil
Professora titular do Programa de Pós-Graduação em Antropologia Social/UFSC e professora visitante do Programa de Pós-Graduação em Antropologia/UFPB. Pesquisadora do CNPq, comitê gestor do Instituto Nacional de Ciência e Tecnologia Brasil Plural e coordenadora do Núcleo de Antropologia do Contemporâneo (TRANSES/UFSC).
\end{abstract}

\section{Mirella Alves de Britto • Universidade Federal de Santa Catarina - Brasil Psicóloga (UNIVALI, 1993), doutora em Antropologia Social (UFSC, 2014) e pesquisadora do Instituto Nacio- nal de Ciência e Tecnologia Brasil Plural e do Núcleo de Antropologia do Contemporâneo (TRANSES/ UFSC).}

Inaê Iabel Barbosa • Universidade Federal de Santa Catarina - Brasil Graduada em Ciências Sociais pela Universidade Federal de Santa Catarina (2019)

\section{Camila Andressa Dias da Silva • Universidade Federal de Santa Catarina - Brasil} Graduada em Antropologia pela Universidade Federal de Santa Catarina (2019)
ORCID: $\odot \odot \odot \odot-\odot \odot \odot 2-2963-9559$ mirebrito@gmail.com
Este artigo tem como objetivo realizar uma leitura etnográfica de prontuários de mulheres internadas no antigo Hospital Colônia Santana (HCS), de Santa Catarina, durante as décadas de 1940 e 1950. Os prontuários fazem parte do acervo do Centro de Documentação e Pesquisa do Instituto de Psiquiatria de Santa Catarina (CEDOPE/Ipq/SC), que abriga a documentação referente ao Hospital Colônia Santana e inclui, além dos prontuários, livros de registro dos internos, livros de ocorrência, relatórios institucionais, fotografias, cadernos, diários, desenhos e pinturas em telas dos internos e outros documentos da instituição. Este artigo traz uma abordagem inicial dessa documentação e busca focar nos modos como os prontuários, ao mesmo tempo que nos informam sobre as práticas médicas e rotinas terapêuticas do hospital, trazem pistas sobre os sujeitos internos, seus atos, condutas, agências e resistências. Nesta análise nos deteremos em alguns poucos prontuários, buscando neles rastros, pistas de algumas dentre centenas de mulheres que ingressaram na instituição durante essas décadas.

Instituição psiquiátrica. Etnografia de arquivos médicos. Prontuários psiquiátricos. Mulher e loucura.
This article aims to perform an ethnographic reading of medical records of women hospitalized at the former Colonia Santana Hospital (HCS), in Santa Catarina, during the 1940s and 1950s. The medical records are part of the collection of the Documentation and Research Center of the Psychiatry Institute of Santa Catarina (CEDOPE/Ipq/ $\mathrm{SC})$, which houses the documentation referring to the Hospital and includes, in addition to medical records, internees' registration books, occurrence books, institutional reports, photographs, diaries, drawings and paintings on screens of inmates and other documents of the institution. This article brings an initial approach to this documentation and seeks to focus on the ways in which the medical records, while informing us about the medical practices and therapeutic routines of the hospital, bring clues about the women internees, their acts, conduct, agencies and resistance. In this analysis we will focus on a few medical records, looking for traces of them, clues from some of the hundreds of women who entered the institution during these decades. 
O objetivo deste artigo é trazer uma leitura etnográfica dos registros documentais do antigo hospital psiquiátrico Colônia Santana, com ênfase nos prontuários psiquiátricos de mulheres internadas nas décadas de 1940 e 1950. Os documentos e registros psiquiátricos nos trazem informações sobre a vida dentro da instituição, os internos, os saberes e as práticas dos profissionais, as rotinas institucionais. Os prontuários, mais especificamente, se constituem em rico material etnográfico sobre os conhecimentos e as práticas médicas, diagnósticos e técnicas terapêuticas; trazem informações sobre as pacientes, em geral focalizados no objetivo médico de descrever sintomas, informações corporais, anatômicas fisiológicas, reações a terapêuticas, mas também descrevem atos, condutas e comportamentos e revelam valores morais e sociais.

Buscaremos, nesta leitura dos prontuários, tomados como verdadeiros "artefa-

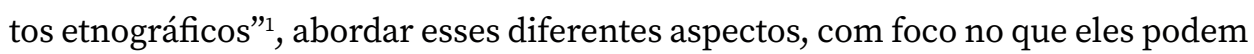
nos indicar sobre as vidas dessas mulheres. Buscamos fazer uma etnografia de arquivo "com sujeitos", privilegiando a abordagem qualitativa e mais detalhada de alguns prontuários. Duas vertentes complementares de análise se cruzam nesta leitura: buscar as práticas e os enunciados científicos e morais contidos nos prontuários, tomados eles próprios como artefatos essenciais dessas práticas; e tomar os vestígios e rastros encontrados nesses documentos como pistas para chegar à vida das mulheres descritas nos prontuários. Ou seja, de um lado, abordamos os prontuários das internas dentro do dispositivo de saber-poder da instituição psiquiátrica, tal como propôs Foucault; e de outro, buscamos o que permaneceu como resíduo na objetificação biomédica produzida no sistema sintoma-diagnóstico-terapêutica ${ }^{2}$.

\section{A instituição: o Hospital Colônia Santana}

O Hospital Colônia Santana, destinado à assistência psiquiátrica no estado de Santa Catarina, foi inaugurado em novembro de 1941, período no qual foram criadas outras duas instituições de saúde pública no estado: a Colônia Santa Teresa, fundada em 1940, dedicada aos pacientes de hanseníase, e o Hospital Nereu Ramos, de 1943, voltado às doenças infectocontagiosas. É também desse período a criação do Abrigo de Menores, em 1940. Era um momento de significativo investimento estatal na reestruturação e na modernização da política de saúde pública no país, centralizada pelo Departamento Nacional de Saúde, e, no caso da assistência psiquiátrica, pelo Serviço Nacional das Doenças Mentais.

A modernização da assistência à saúde mental, em específico, era tanto uma demanda de vários municípios e do estado de Santa Catarina quanto uma exigência do governo federal. Um inquérito sobre as condições dos serviços psiquiátricos nos estados, realizado pelo Departamento Nacional de Saúde (DNS), de 1937 a 1941, havia mostrado que Santa Catarina se encontrava entre aqueles estados em que "a assistência era bastante deficiente, apesar de já existir certa orientação quanto ao tratamento" (Fabricio, 2009, p. 81).

No plano estadual, desde 1905 os sucessivos governos apontavam a necessidade de uma assistência exclusiva e mais modernizada no estado, na capital e
1 Tal como propõem Lowenkron e Ferreira (2014) em sua análise de documentos policiais, a partir da discussão de Riles (2006) sobre o documento como artefato do conhecimento moderno e como artefatos paradigmáticos da pesquisa etnográfica.

2 O diálogo com a proposta da 55 micro-história se torna potente nessa tarefa, principalmente em relação ao paradigma indiciário, proposto por Ginzburg (1990), em que a leitura dos indícios, dos vestígios, se torna um dos procedimentos centrais da pesquisa 
em cidades como Joinville, para tratamento dos alienados (Melo, 2000; Gomes; Pasqualotto; Baptista, 2016.). Até a fundação da Colônia Santana, diferentes destinações eram dadas aos chamados alienados mentais: encarceramento na cadeia pública, envio ao Hospício Pedro II no Rio de Janeiro, às custas do estado, internação no Asilo de Azambuja, de Brusque, gerido pelas irmãs da Congregação da Divina Providência, e ao Abrigo Municipal de Alienados Oscar Schneider ${ }^{3}$, de Joinville, instituições que abrigavam pacientes vindos de diversas cidades do estado. Foram dessas duas instituições que chegaram os primeiros 311 internos do Hospital Colônia Santana no ano de 1942.

Para a historiadora Viviane Borges, a criação do Hospital Colônia Santana representa o começo da institucionalização científica e médica hospitalar da loucura em Santa Catarina (Borges, 2013).

Afastada da capital, em um bairro da cidade de São José, a Colônia Santana tinha todas as características das colônias agrícolas, baseadas no relativo isolamento dos internos e na terapia do trabalho (praxiterapia). No entanto, mesmo que tardia em relação a outros estados, sua fundação aconteceu em um momento em que se iniciava no país a transição desse modelo de assistência para um modelo de hospital colônia, preconizado pelo Departamento Nacional de Saúde e pelo Serviço Nacional de Doenças Mentais ${ }^{4}$. A Colônia Santana foi construída inteiramente com recursos públicos (estaduais e federais), em meio ao projeto de modernização da assistência psiquiátrica no país, tanto do ponto de vista da gestão, quanto das novas técnicas de tratamento. Essa justaposição entre um modelo asilar e assistencial, de um lado, e os novos projetos de administração da saúde pública e das novas técnicas terapêuticas, de outro, marcará as primeiras décadas da Colônia Santana.

Logo após sua inauguração, a administração do hospital foi entregue às irmãs da Divina Providência, a mesma congregação religiosa que administrava o Asilo de Azambuja, em Brusque. As irmãs não apenas tinham uma função central na tomada de decisões e na administração do hospital como se encarregavam de grande parte das funções e tarefas, da limpeza, lavanderia, costura, farmácia, horta, culinária, às funções de enfermagem, como aplicar injeções e soros, fazer curativos, cuidar da higiene dos internos, incluindo os procedimentos mais complexos, como a aplicação de anestésicos (Borenstein et al., 2003). Mesmo os enfermeiros leigos que trabalhavam no hospital eram treinados pelas irmãs. Os primeiros profissionais de enfermagem com formação especializada ingressaram na década de 1970, quando se inicia o declínio da presença das irmãs no hospital e em que é criada a Fundação Hospitalar Catarinense, que passa a gerir os quatro hospitais públicos do estado.

Dos 311 internos em 1942, rapidamente a Colônia Santana chega a 800 até o final da década de 1950, e a 2.200 internos em 1970, situação que Borges (2011) define como o "ápice da superlotação" (p. 1533). Imagens fotográficas registradas nessa década mostram as condições desumanas e de superlotação do hospital ${ }^{5}$.

Essa não é uma situação exclusiva da Colônia Santana: entre 1973 e 1976, há um aumento em $344 \%$ nas internações em hospitais psiquiátricos em todo o Bra-
3 Fundado em 1923 e fechado em 1942, após o qual se tornou presídio político durante o Estado Novo, destinado a descendentes de alemães suspeitos de apoiarem a política do Eixo durante a II Guerra.

4 Em relação à passagem da colônia agrícola ao hospital-colônia, ver o trabalho de Venâncio (2011) sobre o caso da Colônia Juliano Moreira, no Rio de Janeiro.

5 Trata-se de um álbum de fotografias, encontrado no acervo de imagens do Centro de Documentação e Pesquisa (CEDOPE) do Instituto de Psiquiatria (IPQ/SC), retratando as condições dos pacientes internados no hospital nesse período. Segundo a historiadora Viviane Borges (2013), essas imagens, feitas na década de 1970, teriam um caráter de denúncia das condições do hospital "como um espaço decadente, superlotado, povoado por pacientes nus, amontoados em celas, sob [sic] colchões de capim, ou no chão" (p. 130). 
sil. Nesse momento uma série de denúncias públicas sobre as condições dos manicômios do país começa a aparecer, culminando com a crise no Departamento Nacional de Saúde Mental (DINSAM), em 1978, que envolveu uma greve e denúncias da situação dramática das instituições psiquiátricas, nas quais os internos eram vítimas de agressão, estupro, trabalho escravo e mortes. Apesar da demissão de 260 profissionais e bolsistas do órgão, esse movimento desencadeou novas denúncias, mobilizações, principalmente por parte dos trabalhadores da saúde mental (Amarante; Nunes, 2018) ${ }^{6}$. O desfecho dessas denúncias e mobilizações foi a criação de vários movimentos ligados à luta antimanicomial e pela reforma do sistema de assistência psiquiátrica no país, desembocando, em 2001, na aprovação da Lei da Reforma Psiquiátrica. A política nacional de saúde mental adotada a partir da Lei determinou o fechamento progressivo dos leitos em hospitais psiquiátricos e a criação das redes psicossociais, um extenso programa de atenção à saúde mental fundamentado na atenção básica e nos centros de atenção psicossocial (os CAPS), e em programas como o Volta pra Casa, destinado aos egressos de longa internação nos hospitais.

Em 1996, o Hospital Colônia Santana passa a se denominar Instituto de Psiquiatria de Santa Catarina (IPq/SC), e um dos efeitos da Reforma Psiquiátrica foi a criação das Residências Terapêuticas, que abrigam homens e mulheres que viveram como internos por mais de vinte anos e perderam o vínculo com suas famílias e locais de origem. Mas o IPq não deixou de receber novos internos, mesmo com as diretrizes da Reforma Psiquiátricas. Ele ainda é o principal espaço público de atendimento emergencial em psiquiatria no estado, recebendo inclusive menores de idade, em processo de internação compulsória a partir de mandados judiciais obrigatoriamente atendidos pela direção do hospital ${ }^{7}$.

A história e a crítica da instituição manicomial é um tema que já tem uma longa trajetória, na qual o trabalho arqueológico de Michel Foucault (1978), em História da loucura na Idade Clássica, é uma referência incontornável. Essa obra e trabalhos posteriores de Foucault, como o curso O poder psiquiátrico, de 1973-1976 (Foucault, 2006), abriram o caminho para se pensar a instituição psiquiátrica como dispositivo de saber-poder ${ }^{8}$. Para Foucault (1978), o que viabilizou o surgimento da psiquiatria foi um conjunto de relações entre hospitalização, procedimentos de exclusão, produção de leis, a moral burguesa e as normativas nas relações de trabalho. Nesse sentido, a psiquiatria, para além de uma disciplina, pode ser tomada como um dispositivo, uma lógica que se constitui em relações entre discursos, arquitetura, enunciados científicos, instituições, proposições morais, regulamentos, ditos e não ditos ${ }^{9}$.

Além de Foucault, outros autores refletiram de modo crítico sobre a instituição psiquiátrica, como Castel (1977), quanto à ordem psiquiátrica; Goffman (1998 [1961]), sobre o manicômio como instituição total; Szasz (1979), com a crítica ao modelo organicista na psiquiatria. Além daqueles que buscaram uma alternativa ao manicômio e à psiquiatria tradicional, fundando as bases da antipsiquiatria, das lutas antimanicomiais e dos movimentos de reforma psiquiátrica, como Basaglia (1985 [1968]); Cooper (1982); Laing (1987 [1967]); Cooper e Laing (1982 [1964]).
6 Uma das primeiras denúncias sobre a situação dos hospitais psiquiátricos brasileiros foi a reportagem "Sucursal do inferno", sobre o Hospital Colônia de Barbacena, Minas Gerais, publicada na Revista O Cruzeiro, em 1961. Em 1979, o psiquiatra italiano Franco Basaglia, em visita ao mesmo hospital, associa as condições do hospital aos campos de concentração nazistas.

7 Conforme presenciamos em uma de nossas primeiras visitas ao IPq, em abril de 2016, e confirmado em conversa informal com funcionários do IPq.

8 Sobre as diferenças da abordagem de Foucault entre História da loucura, e o curso de 1973-74, sobre o Poder psiquiátrico, ver o artigo de Caponi, 2009. Nele a autora mostra como o foco em uma arqueologia dos saberes psiquiátricos, em História da loucura, se desloca para uma genealogia do poder psiquiátrico, incidindo na produção de um sujeito (louco ou doente mental)

9 Cf. Foucault, 1979, p. 244. 
No Brasil, uma série de pesquisas feitas em fontes clínicas e institucionais dos antigos hospícios e das colônias de alienados proporcionou abordagens sobre a história da psiquiatria no país com foco em saberes, técnicas, práticas diagnósticas e terapêuticas praticados no interior dessas instituições ${ }^{10}$. Mais recentemente, pesquisas têm se voltado à tentativa de compreender a vida e a trajetória dos sujeitos internados. Isso tem sido feito tanto através fontes documentais, principalmente aquelas produzidas pelos próprios sujeitos, como cartas, diários, cadernos $^{11}$, quanto através de pesquisas de campo feitas diretamente com os sujeitos internados, moradores, egressos ou com os profissionais de hospitais, clínicas, asilos e comunidades terapêuticas ${ }^{12}$.

A abordagem que propomos neste artigo reconhece a importância da perspectiva que aborda a instituição a partir dos dispositivos de controle, vigilância e saber-poder da medicina. Essas dimensões estão presentes na documentação pesquisada e nos prontuários analisados. Ao mesmo tempo, consideramos importante entender as conexões entre esses saberes e controles biomédicos, os valores morais predominantes nos contextos históricos em questão e buscar as vozes, experiências, agências, resistências dos sujeitos englobados pela instituição asilar.

A etnografia no arquivo da instituição psiquiátrica, ao assumir a tarefa da reconstrução narrativa das vidas contidas nos documentos, dialoga com a ideia referenciada por Wadi (2011) de uma história com sujeitos, a partir do que a autora define como a abertura de um "novo cenário analítico" (idem, p. 250), composto pelo reconhecimento de novas fontes para a historiografia das instituições psiquiátricas e pelo foco no dia a dia da instituição e na experiência dos sujeitos (Wadi, 2011, p. 253). Entre as novas fontes, encontram-se livros de registros, prontuários e textos e cartas produzidos pelos próprios internos. É sobre esses últimos que Wadi se debruça, analisando as cartas de uma interna no Hospital São Pedro, de Porto Alegre entre 1909 e 1911.

O desafio que nos colocamos na pesquisa foi o de buscar esses sujeitos na leitura oblíqua de narrativas, relatos, anotações, descrições não produzidas diretamente pelos internos, mas pelos profissionais que integravam a instituição: livros de registros, de ocorrência, e no objeto foco deste artigo, os prontuários. Isso implica na tarefa analítica de uma leitura prospectiva e a contrapelo dos prontuários, buscando o que não é evidenciado diretamente, mas permanece como resíduos ou rastros de condutas, atos e resistências descritos por terceiros.

Tendo como fontes centrais os documentos produzidos dentro da instituição e pelos profissionais que nela atuaram, este trabalho, tal como propõe parte da historiografia contemporânea, baixa algumas escalas ${ }^{13}$ na complexa história da instituição, se ocupa da análise das vidas nela abrigadas, buscando histórias, experiências, agências, resistências dos sujeitos, das quais não são acessíveis mais do que rastros, pistas, sinais.

Uma dessas questões que nos colocamos nesta abordagem da instituição manicomial foi a de quais seriam os agenciamentos sociais possíveis por parte daquelas que, uma vez internadas, são tomadas como "incapazes" ${ }^{14} \mathrm{e}$ submetidas ao regime disciplinar e tutelar da instituição, a processos de despersonalização ${ }^{15}$, a
10 Como é o caso do clássico Danação da norma, de Machado et al., 1978; Cunha, 1986; Carrara, 1998; Engel, 2001; Portocarrero, 2002; Venâncio; Potenguy, 2015; Venâncio, 2011; entre outras.

11 Para citar alguns desses trabalhos, Facchinetti, 2008, 2010; Borges, 2013; Wadi, 2009a; 2011;

12 Biehl, 2005; Andrade, 2012; Andrade; Maluf, 2014; Saretta, 2014; entre outros

13 No sentido da discussão de Jacques Revel (2010) sobre a "variação de escalas" de observação na micro-história.

14 Até muito recentemente (Lei 13.146/2015, Lei Brasileira de Inclusão da Pessoa com Deficiência), o doente mental era definido, nas diversas legislações, como incapaz.

15 Através do uso de uniformes padronizados, rotinas coletivas, distanciamento da vida familiar e da própria casa. 
vigilâncias e escrutínios constantes. Algumas com diversas entradas e altas, outras que rapidamente foram colocados em condição de cronicidade ${ }^{16}$, muitas delas permanecendo na instituição até morrer, tendo como "motivo da alta" o óbito, conforme constatamos nos registros analisados ${ }^{17}$. É importante ter como ponto de partida a ideia de que as internas não são em si incapazes de refletir ou agir por conta própria. No entanto, a situação manicomial determina essa condição de incapacidade não apenas pela avaliação clínica da pessoa em internação e pelo estabelecimento de um diagnóstico psiquiátrico, como através de todo um aparato de contenção, isolamento, controle e vigilância.

Como explicado anteriormente, existe uma grande produção acadêmica sobre a instituição manicomial, com foco nos regimes disciplinares, de controle e de violência institucional. Nossa abordagem não deixou de fora essas dimensões, no entanto, além disso, buscamos entender o quanto é possível dar visibilidade aos sujeitos que por ali passaram, que ali viveram, e às suas improváveis, mas não impossíveis, resistências, agências, e mesmo tentativas de "habitar" o manicômio, no sentido de constituir ali alguma vida vivível ${ }^{18}$.

\section{O desafio da etnografia em arquivos psiquiátricos}

Mesmo sendo um território tradicional da pesquisa historiográfica, a pesquisa em arquivos tem ocupado espaço na antropologia (Cunha, 2004; Giumbelli, 2002), dando grande ênfase às implicações metodológicas, éticas, epistemológicas da confluência entre pesquisa etnográfica e arquivo.

A etnografia em arquivo tem se desenvolvido no Brasil em três modos de abordagem. O primeiro é o que foca nos arquivos produzidos pelas próprias pesquisas antropológicas, como arquivos etnográficos e acervos de antropólogos/as - como notas de campo, diários, desenhos, registros fotográficos ou filmes etc. ${ }^{19}$. O segundo modo toma o arquivo como uma fonte suplementar e secundária da pesquisa de campo, que ajudaria a estabelecer contextualizações sociais e históricas dos eventos observados ou narrados pelos interlocutores da pesquisa. O terceiro modo aborda o arquivo como campo prioritário da pesquisa, como o território em que as vozes, as perspectivas ou pontos de vista, os acontecimentos serão "observados" e em que a questão que se coloca é produzir narrativas a partir de "imagens e vozes de um tempo distante" (Cunha, 2005, p. 36).

Carrara, em sua pesquisa sobre o surgimento do manicômio judiciário no Brasil, traz a ideia de uma "aldeia-arquivo" (1997, p. 53) para discutir a especificidade de uma pesquisa etnográfica feita em arquivos de instituições psiquiátricas, espaço no qual não conseguimos obter nada além de fragmentos. É possível que as anotações nos prontuários, nos livros de registro e de ocorrência que pesquisamos sejam os únicos fragmentos restantes das vidas ali anotadas, além da memória e histórias contadas por algum parente ou familiar que possa relembrar uma avó ou uma tia que havia "enlouquecido" e desaparecido no esquecimento do manicômio. Nessa medida, além de ter o arquivo como o campo da pesquisa etnográfica, o documento, no caso o prontuário, é tomado como um artefato etnográfico que não só armazena usos, práticas, técnicas, saberes, valores, rotinas,
16 Com diversas internações de curta ou longa duração no hospital.

17 Informação inserida tanto nos prontuários quanto nos livros de registro.

18 No sentido dado por Butler, indagando sobre que situações tornariam muito difícil a possibilidade de uma vida vivível (2004).

19 Por exemplo, as pesquisas de Cunha (2004; 2005) em arquivos e acervos etnográficos de pesquisas antropológicas com populações afro-americanas, como os arquivos de Ruth Landes. 
normas, agências e relações, como se constitui ele próprio em um objeto central da vida manicomial.

Se o trabalho de descrição e análise etnográficas buscam construir algum tipo de totalização a partir de fragmentos, no caso desta pesquisa os fragmentos são mínimos em dimensão e dispersos, situação que pode parecer paradoxal diante do caráter relativamente fechado do prontuário psiquiátrico, modo de afirmar a objetividade e a cientificidade das informações que contém. Não pretendemos construir uma história social do hospital Colônia Santana, mas fazer uma leitura etnográfica dos documentos que nos permita buscar vestígios de relações e subjetividades envolvidas na trama dos dispositivos institucionais. Para tornar possível, essa tarefa foi necessário, de certo modo, "entrar em relação" com o material que tínhamos em mão e com os fragmentos de vidas ali contidas, testando estranhamentos, exercitando comparações, especulando sobre possíveis leituras de uma breve anotação.

A discussão de Foucault (1969) sobre o arquivo e a abordagem arqueológica, que busca as condições de surgimento de determinados enunciados, nos ajudou a pensar sobre os enunciados científicos e morais presentes da documentação analisada. $\mathrm{O}$ conceito de enunciado nos ajuda a entender os regimes de verdade produzidos dentro da instituição psiquiátrica a partir de seus diversos mecanismos, da arquitetura e organização dos corpos no espaço do hospital psiquiátrico, aos diversos procedimentos que definem a rotina da instituição. De cada prontuário lido, emergiram não apenas enunciados discursivos de todo tipo, mas também práticas, objetos (substâncias, máquinas, móveis), atos. Essa abordagem nos ajudou também a entender os modos de organização e distribuição dos enunciados entre os diferentes registros, como os múltiplos formulários, registros e fichas de controle de cada paciente: o formulário do registro de entrada; os prontuários, organizados também no modo de formulário, cada vez mais detalhado, esquadrinhado, objetivado e racionalizado, como veremos mais adiante.

Quando afirmamos buscar os sujeitos no arquivo, é preciso explicar sobre de que sujeito estamos falando. A concepção de sujeito está diretamente ligada ao modo como abordamos o arquivo. Estamos aqui pensando, com Foucault (1979), para além da ideia de um "sujeito soberano" ${ }^{20}$, cuja abordagem seria mais apropriada a uma visão de arquivo como registro de uma verdade cristalizada e compondo uma história linear. Uma abordagem etnográfica e micropolítica do documento nos permite, num primeiro momento, entender como se fala desse(s) outro(s), e de que modo relações de poder atravessam esses registros sobre o outro. No arquivo psiquiátrico, o prontuário, por exemplo, é produzido pelo médico (sujeito do saber sobre corpo e a mente do paciente) e que enuncia verdades sobre este (através do diagnóstico, das descrições sobre seu estado somático e psíquico), assim como anota acontecimentos importantes (necessidade ou não de internação, terapêuticas, possibilidade de alta, saída do hospital, óbito). Como veremos, muito mais é anotado. Além do psiquiatra, outros profissionais ajudam a produzir os prontuários, como enfermeiros, auxiliares, práticos, tarefas que nos primeiros anos da Colônia Santana foram em grande parte realizadas pelas freiras. A hierar-
20 Que poderia ser definido também a partir da noção de uma "metafísica da substância", ou seja, a ideia de um sujeito prévio à experiência social e às relações de poder (Butler, 1990). 
quia do hospital se expressa também no prontuário, entre anotações burocráticas de data e horário de entrada, anotação de diagnósticos e prescrições, controles cotidianos do estado das pacientes e das terapêuticas empregadas ${ }^{21}$.

Neste artigo nos colocamos a tarefa de explorar essa dupla dimensão do documento (no caso aqui, dos prontuários): de um lado, no que eles nos falam sobre os saberes e poderes psiquiátricos, sobre os modos como inscrevem o sujeito no discurso de verdade contido no prontuário; de outro, na leitura oblíqua dos rastros, pistas e vestígios deixados marginalmente sobre as mulheres a que se referem ${ }^{22}$.

\section{O arquivo}

As fontes com que trabalhamos estão abrigadas atualmente no Centro de Documentação e Pesquisa do Instituto de Psiquiatria de Santa Catarina (CEDOPE/ IPq/SC), criado em novembro de 2011.

Segundo nos contou a enfermeira e coordenadora do CEDOPE, Eliani Costa, em nossa primeira visita ao IPq, alguns anos atrás um diretor da instituição, necessitando liberar espaço, retirou um volume grande de "papel velho" de uma sala e o depositou no pátio interno do Hospital. Ao perceber que uma parte da memória da instituição seria jogada no lixo, essa profissional decidiu salvar o material e acondicioná-lo em outro local. Ali começou um trabalho que tem se estendido por alguns anos já, de constituição de uma memória documental do antigo Hospital Colônia Santana.

No período de realização da pesquisa, o CEDOPE contava com três salas no andar térreo do prédio central do Hospital, onde fica a administração (com o computador que dá acesso aos prontuários digitalizados); uma salinha agregada a esta, onde está o acervo de imagens, composto por fotografias, álbuns de fotografias e vídeos em VHS; uma sala de exposições (com objetos antigos do hospital, o primeiro livro de registros e outros documentos expostos - reorganizada em 2016 para a comemoração dos 75 anos do Hospital, à qual foi agregada, no corredor que dá acesso à sala, a galeria dos retratos dos diretores do hospital); e o chamado Cedopinho, uma sala menor onde é feita a higienização e organização dos documentos, na qual tivemos acesso a diversos livros de registros das décadas de 1940 e 1950, e onde se encontra também um fichário indexador. Além dessas, o CEDOPE ocupava um salão maior na antiga Ala Oitava do Hospital, hoje desativada e em reforma para abrigar o futuro ambulatório psiquiátrico. Nesse salão estava a maior parte da documentação do acervo, todos os prontuários, dispostos em caixas numeradas conforme os lotes de digitalização, organizadas por ordem de numeração e cronologia; e os livros de ocorrência ainda empilhados no chão, cobertos de poeira e insetos, sem higienização e aguardando as estantes em que seriam dispostos e organizados.

É importante mencionar as condições em que encontramos o acervo e o fato de que, efetivamente, para conseguir começar a trabalhar com os prontuários físicos, tivemos que realizar alguns mutirões de higienização e organização. Esse trabalho foi um dos acordos de reciprocidade que fizemos com a instituição. Cabe aqui mencionar o diagnóstico feito por Facchinetti et al. (2008) sobre o quanto as
21 Aqui é importante trazer a interessante análise de Mário Teixeira sobre as relações de poder e hierarquia dentro do Hospital Colônia Santana. Nesse trabalho, ele analisa os diversos modos com que setores diferentes do hospital constituem dispositivos de saber-poder, em uma hierarquia vertical do diretor do hospital (sempre um médico) ao atendente, funcionário com nenhuma formação na área, mas que lida diretamente com os pacientes internos no cotidiano do hospital e que fundamentalmente maneja as informações diárias referentes a esses pacientes (Teixeira, 1993).

22 Gomes et al. (2016), no campo da psicologia social, se propõem a fazer uma análise da documentação do extinto abrigo de alienados de Joinville (SC), tendo como referência o paradigma indiciário, buscando os rastros de memória presentes nos registros da instituição. Seu foco são imagens, livros de registro, reportagens que retratam a instituição e sua relação com a cidade. 
condições de higienização e organização das fontes primárias das instituições psiquiátricas têm dificultado a realização de pesquisas mais sistemáticas sobre a história e a vida dessas instituições.

O acervo do CEDOPE é composto por diferentes tipos de documentos, que incluem os Livros de Registros (em que eram feitos os registros de ingresso no Hospital); os Prontuários (em que eram anotadas as informações sobre cada paciente, abrangendo diagnóstico, prescrições de tratamento, altas e reinternações, observações de acompanhamento e outros eventos); os Livros de Ocorrência (um tipo de diário do Hospital, em que eram anotados todos os fatos ocorridos diariamente dentro da instituição, envolvendo os pacientes ou outras ocorrências); fotografias e vídeos (registros de festas, passeios, espaços do hospital, registros sobre modificações e melhorias realizadas por determinadas gestões, etc.); relatórios de gestão; produções dos próprios internos (desenhos, telas, poemas, diários, etc.).

Desde o início da pesquisa de campo em 2015, trabalhamos com os Livros de Registros, os Prontuários, as fotografias e um relatório de gestão. Chegamos a manusear e ler alguns livros de ocorrência, mas estes se encontravam em condições ainda precárias de armazenamento e organização. Apesar de ainda não estarem organizados para poderem ser pesquisados com sistematicidade, esses livros de ocorrência trazem relíquias sobre a vida cotidiana do Hospital, como narrativas sobre fugas, rebeldias, punições, protocolos e rotinas (como o protocolo do cigarro, estabelecido da década de 1990, que determina como e onde se podia fumar cigarro no hospital, e que funcionava também como dispositivo de punição: caso um interno desrespeitasse alguma regra interna, perderia sua vez e horário de fumar).

A organização do CEDOPE é também resultado de trabalho realizado pela equipe de pesquisadoras coordenada pela profa. Viviane Borges da Universidade do Estado de Santa Catarina (UDESC), juntamente com a enfermeira do IPq Eliani Costa $^{23}$. Através do Projeto Arquivos Marginais, essa equipe colaborou com o processo de salvaguarda (higienização e acomodação) dos cerca de 22 mil prontuários do CEDOPE ${ }^{24}$.

Existe uma versão digitalizada dos prontuários, feita através de um projeto de digitalização dos acervos de saúde do estado de Santa Catarina. Parte da pesquisa foi feita nela. No entanto, é um acervo digital difícil de trabalhar, tanto pelo acesso restrito, quanto pela falta de dispositivos de busca a não ser uma lista de pacientes, sem outros dados além do nome, número do prontuário e número do lote (caixa física) em que estão armazenados. Não é possível, por exemplo, fazer uma busca com outra variável que não o nome ou o número de prontuário. Isso dificulta uma busca por data ou período, sem que se tenha que procurar previamente os dados nos livros de registro correspondentes a essas décadas.

Além dessas dificuldades quanto ao acesso aos documentos, enfrentamos os demais obstáculos próprios da pesquisa em instituições da área de saúde, que envolvem os trâmites nos comitês de ética, desconfianças por parte dos agentes e funcionários, dispositivos de controle que dificultam a pesquisa, além da falta de compreensão por parte da direção e dos gestores de instituições de saúde so-
23 Que colaborou com nossa pesquisa abrindo as portas do CEDOPE e permitindo o acesso aos prontuários eletrônicos e demais documentos do acervo.

24 Processo analisado em Viana (2013) e Borges (2016). 
bre a importância de salvaguardar e manter o arquivo e a memória documental da instituição.

\section{Registros}

Antes de iniciar a abordagem dos prontuários, vamos descrever muito brevemente os outros documentos trabalhados. Neles encontramos informações que futuramente poderão ser associadas à leitura dos prontuários, como certos marcadores sociais, origem e profissão das mulheres que entraram nas primeiras levas de pacientes do hospital, as fotos do berçário e a internação de crianças, entre outros temas.

\section{Fotografias e álbuns fotográficos}

No material fotográfico levantado ${ }^{25}$, encontramos registros de festas e comemorações; passeios; fotografias que buscam retratar o espaço da instituição, as mudanças e melhorias feitas em determinadas administrações e gestões, provavelmente utilizadas em relatórios de gestão; álbum inteiro de fotografias retratando as condições desumanas em que se encontravam os internos, que teriam sido tiradas por um funcionário para efetuar uma denúncia sobre as condições do hospital (cf. nota 5).

Num primeiro momento, nosso interesse era o de buscar fotos que registrassem o cotidiano da instituição. No entanto, quando começamos a folhear as fotos das festas e comemorações, algo interessante começou a aparecer: nesses momentos, percebiam-se situações de troca afetiva, interação, brincadeira, uso de fantasias e maquiagens. É de uma das festas, a foto de um rapaz muito jovem, com vestido e maquiagem, em meio a fotos de várias outras pessoas com diferentes fantasias, dançando em um salão de baile. O lúdico, imprevisto nos protocolos hospitalares, era resultado da iniciativa das funcionárias do hospital, que, lá na ponta da vida cotidiana da instituição, reinventavam a política institucional e criavam situações em que era possível um outro modo de habitar a instituição, para além dos protocolos médicos estabelecidos.

Assim, as fotos registram vários momentos festivos, com dança, fantasia, máscara e maquiagem. Registram também um passeio (excursão) a uma praia, com fotos detalhadamente organizadas em um álbum e com legendas descrevendo os personagens de cada foto. Ali se reúnem internos e profissionais, em brincadeiras na praia, em roupa de banho, posando para o fotógrafo, almoçando ou lanchando juntos em volta de uma mesa.

No registro das alas e espaços internos, nos surpreenderam as fotos da ala feminina, contendo vários berços com crianças pequenas. Como os berços estavam dentro da Ala, pressupomos que fossem filhos de mulheres internas, provavelmente nascidos no próprio hospital. Essas imagens complementam algumas situações que percebemos nos prontuários de mulheres, em que a condição de gestação é identificada e assinalada.

O paralelo entre os álbuns de registro interno da instituição (espaços, alas etc.) e os de registro de atividades lúdicas (passeios, festas e comemorações) mostra
25 Através de bolsa de Iniciação Científica (PIBIC) de Camila Dias, que pesquisou e digitalizou as fotografias e álbuns do acervo. 
alguns contrastes entre a rotina altamente normatizada e controlada do hospital, inclusive na organização do espaço e na arquitetura do prédio, e o lúdico como momento de invenção e criação de outros modos de relação, de apresentação de si, de afetividade, que não estão nos protocolos terapêuticos, mesmo reconhecendo que também nessas situações os controles e hierarquias permaneciam.

\section{Os Livros de Registros - o Livro no. 1}

Inaugurado em 1941, os primeiros internos do Hospital Colônia Santana, que chegaram no ano seguinte, foram provenientes de dois outros hospitais psiquiátricos de Santa Catarina: o Abrigo Municipal de Alienados Oscar Schneider, de Joinville, criado em 1923, e o Hospício Azambuja, de Brusque, criado em 1902 pelas irmãs da Divina Providência, ambos da região do Vale do Itajaí. Foram ao todo 311 transferências, sendo que o Livro de Registros no. 1, que tem em torno de 700 páginas, traz justamente a internação dessa primeira leva de pacientes proveniente dessas duas instituições, com a data de 6 de janeiro de $1942^{26}$. O formulário que consta em cada página do livro de registro traz informações sobre as pessoas que deram entrada no hospital. Bem no alto, no meio da página, um cabeçalho com o nome do Serviço de Assistência a Psicopatas, logo abaixo o número de Registro Geral e a seguir informações como nome, residência, procedência, nacionalidade, data de nascimento, sexo, instrução, religião, altura, profissão, estado civil, filhos, mulher ou marido, bens, internante, informante, data de entrada, evasão, alta experimental, alta definitiva, data de falecimento, nome do pai, cor, endereço e naturalidade, o mesmo para a mãe, estado civil dos pais. Em uma coluna, à direita do formulário de registro, consta um espaço para se anexar foto e um item de observação, com espaço a ser preenchido abaixo. Entre as observações anotadas, constam as datas de retorno após alta, informações sobre o estado do paciente, eventuais correspondências recebidas de familiares ${ }^{27}$.

Na maior parte dos registros de mulheres desse período, a profissão descrita é de "doméstica". No entanto, a sinalização "doméstica" no formulário de entrada não necessariamente significa que a mulher a que se refere tenha suas atividades restritas ao "lar" (ou dona de casa), ou que fosse empregada doméstica (menor possibilidade, no caso do período analisado e dos locais de proveniência delas, cidades do interior de Santa Catarina). Levando-se em consideração que grande parte dos homens internados no mesmo período tinha como profissão a de "lavrador", infere-se que as mulheres poderiam ter atividades no trabalho rural também ${ }^{28}$. Essa é uma questão que ainda merece ser analisada com mais detalhamento a partir dos livros de registro e na comparação com períodos posteriores à década de 1940. Outro dado interessante nos registros de internação das mulheres é em relação ao fato de que, em geral, o informante é o marido, no caso das mulheres casadas, ou o pai, no caso das solteiras.

Uma questão importante que apareceu nos livros de registro, e não apenas na década de 1940, são os registros de entrada de crianças e jovens (menores de 18 anos), conforme aponta o levantamento inicial ${ }^{29}$.
26 O primeiro Livro de Registros do HCS foi pesquisado e digitalizado por Inaê label Barbosa, na época bolsista de Iniciação Científica (PIBIC).

27 Esse mesmo formulário se repetirá na primeira página do prontuário.

28 O reconhecimento da profissão de agricultora é muito recente, sendo que a profissão de pescadora, por exemplo, nem era reconhecida até recentemente (ver Gerber, 2013).

29 Feito por Mirella Alves de Britto. 


\section{Os prontuários}

Finalmente, então, chegamos aos prontuários ${ }^{30}$, que, como colocado, estão disponíveis no CEDOPE em dois formatos: em sua forma física, em processo de organização e classificação durante a pesquisa, e digitalizados.

No caso dos prontuários físicos, a dificuldade maior se deu pelo fato de ainda estarem em processo de organização e classificação por ordem cronológica nas estantes $^{31}$. No caso dos prontuários digitalizados, a consulta só pode ser feita em um computador, localizado na sala da secretaria do CEDOPE, e que nem sempre estava disponível. Não era possível fazer o download do prontuário digitalizado, então era preciso transcrevê-lo manualmente.

Outra dificuldade da pesquisa nos prontuários é a legibilidade, tanto por problemas de escaneamento, quanto da caligrafia dos profissionais que fizeram as anotações. A escrita médica é um tema que evoca várias questões, que vão desde as dimensões restritivas de uma escrita profissional feita no formato de um formulário, e seguindo regras institucionais, às questões de caligrafia e criptografia das informações ${ }^{32}$.

Os prontuários são formulários extensos, que incluem informações sobre as pacientes (nome, estado civil, religião, procedência, filhos, etc. e o diagnóstico), partes com tabelas de dados orgânicos e fisiológicos (resultados de exames, tabela de controle de ciclo menstrual); controle de terapêuticas (medicamentos administrados, tabela de praxiterapia, tabelas de aplicação de eletrochoque e insulinoterapia), entre outras informações orgânicas e fisiológicas detalhadas; e partes mais descritivas, em que se incluem perguntas sobre doenças na família e antecedentes hereditários, comportamentos e histórico da doença, exame psíquico, observações etc.

Como colocou Mário Teixeira (1993), em sua pesquisa sobre a Colônia Santana, mais que outros prontuários clínicos, os prontuários psiquiátricos têm uma dose alta de subjetividade em suas descrições. Percebemos isso não apenas nas partes dos prontuários destinadas a anotações sobre condutas, comportamentos e atitudes das pacientes, como o "Histórico da Doença” ou "Ato Extravagante", mas também na resposta a questões que poderiam ser tomadas como objetivas, como o "Exame somático".

Há diferenças notáveis entre os prontuários dos anos 1940 e os da década de 1950, que indicam mudanças nas práticas, técnicas terapêuticas e concepções de causas e origens das doenças e modos de determinação de diagnósticos. No prontuário dos anos 40, há uma parte longa denominada "Esquema de constituição", contendo os dados antropométricos do paciente, como circunferência e diâmetro do crânio, altura da face, comprimento e largura do nariz, largura e circunferência do peito e abdômen e tipo morfológico. Há uma preocupação com as informações referentes a antecedentes hereditários da doença, incluindo a existência na família de situações de suicídio, alcoolismo, homicídio, toxicomanias e outros "temperamentos anormais” (cf. os prontuários). Nas prescrições medicamentosas dessa década, incluídas na "Folha de Controle das Prescrições Médicas”, é comum o uso de medicamentos para sífilis (existe inclusive uma tabela específica de tratamento
30 Pesquisados e transcritos por Sônia Weidner Maluf.

31 Uma tarefa que realizamos conjuntamente com a equipe de pesquisa da UDESC, coordenada pela professora Viviane Borges, que já vinha se dedicando à higienização e organização do material do acervo.

32 Para Thiaudière (2012), a receita médica se inscreve num campo semântico inacessível ao paciente (p. 29). Emprego de nomes especializados, abreviaturas, e uma escrita muitas vezes ilegível só aumentam a dificuldade de acesso ao conteúdo para quem é leigo. A receita se destina ao farmacêutico, não ao paciente (ou à pesquisadora). 0 mesmo se aplica à redação do prontuário médico, destinado a ser lido por quem dará continuidade ao tratamento e às anotações (médicos, enfermeiros). 
antiluético ${ }^{33}$ ), mesmo não havendo nos prontuários um diagnóstico prévio ao tratamento $^{34}$. Entre os medicamentos para sífilis, o arsênio e o bismuto, utilizados na profilaxia de gestantes para evitar contaminação do feto. Também encontramos entre as prescrições dessa década as vacinas contra tifo.

Outros tratamentos comuns são feitos com várias tinturas fitoterápicas, como de ópio, boldo, abacateiro, beladona, valeriana etc., o que pode estar ligado às práticas das irmãs da Divina Providência na época. Também encontramos menções à prescrição de Tiazamida, medicamento à base de sulfa, considerado nos registros médicos daquela época a "nova descoberta" contra vários tipos de infecção bacteriana (Barros, 1942). Tanto as prescrições terapêuticas quanto o tipo de informação sobre os pacientes mudam no prontuário do final da década de 1940 e início da de 1950. São incluídas tabelas de aplicação de terapêuticas como eletrochoque (também utilizadas para aplicação de cardiazol) e insulinoterapia - três terapias de choque que serão utilizadas nas décadas seguintes como a terapêutica central do HCS. A partir dessa década também não é observado mais o uso das tinturas fitoterápicas entre os medicamentos.

Há também nos prontuários uma parte diferenciada para homens e mulheres, referente à vida sexual/vida reprodutiva e filhos na "Folha de Informação sobre o doente". Na parte a "ser respondida se o doente for homem", as perguntas são destinadas à vida sexual (“Em que idade teve os primeiros contatos sexuais?”); doenças venéreas (“Contraiu alguma doença venérea?”), impotência (“Já esteve impotente alguma vez?”), casamento, filhos, doenças ou morte dos filhos. No item destinado exclusivamente às mulheres, as perguntas estão direcionadas ao ciclo reprodutivo: "Em que idade começou a ser menstruada?", "Quantos dias costumava durar a menstruação?”, "Vinha esta regularmente todos os meses?”, "Sofria de cólicas menstruais?", “Já teve hemorragias?”, "Se é casada, em que idade casou-se?”, “Tem filhos? Estado de saúde deles:”, “Se algum é morto qual a causa:”. Além desses dois itens, a Folha de Informações sobre o Doente traz, em sua primeira página, a pergunta "Houve abortos?", dificilmente deixada em branco quando se tratava de mulheres casadas. Percebe-se, ainda, um controle sistemático da menstruação das mulheres, com uma tabela específica em que todo mês se anota o dia e a duração desta, assim como comentários em destaque sobre interrupção da menstruação.

Desses prontuários, vamos nos deter especificamente em quatro. São utilizados nomes fictícios e omitidos o número do prontuário e o local exato de procedência da interna, visando preservar a identidade das mulheres, apesar da antiguidade desses documentos.

A leitura de cada seção do prontuário ajuda a entender as concepções e influências hegemônicas da psiquiatria em cada período (Fachinetti et al., 2010). A leitura dos dados que trazem sobre cada indivíduo em particular nos ajuda a extrair narrativas singulares de cada uma dessas histórias e trajetórias de vida, de sofrimento, adoecimento e tratamento. Ao mesmo tempo, os acontecimentos narrados são surpreendentemente comuns entre as mulheres internadas nas décadas analisadas. Se a leitura dos prontuários evidencia o percurso medicali-
33 Termo utilizado para medicamentos de tratamento da sífilis.

34 Isso foi observado por Viana em sua análise dos prontuários de menores internados no HCS. Muitos deles eram submetidos ao tratamento antiluético sem terem o diagnóstico. Cabe lembrar, junto com a autora, que o combate à sífilis se tornou uma política pública central no início do século XX, vista como uma doença matriz de outras, inclusive de ordem psiquiátrica (Viana, 2015). 
zador do diagnóstico e do tratamento e o que eram os dispositivos da psiquiatria científica do período, ela também evidencia as apreensões morais da loucura e dos atos classificados como loucura, inclusive na caracterização da doença. O modelo médico não apenas deixava escapar modelos morais, mas se fundamentava grandemente neles.

Os prontuários referentes à década de 1940 foram acessados em sua versão digitalizada, trazendo mais dificuldades de leitura em função da má qualidade da digitalização de algumas folhas. Para os prontuários que se estendem para além das décadas de 1940 e 1950, indicando uma longa permanência da interna, nos ativemos à análise das anotações nessas duas décadas, mesmo trazendo algumas referências sobre as anotações das décadas seguintes. Os prontuários referentes aos anos 1950 nos permitiram compor narrativas mais detalhadas sobre as internas em função dos dados encontrados.

Vamos, então, a alguns desses prontuários.

\section{Vera}

Nascida em 1895, Vera ingressou no HCS em janeiro de 1942, na primeira leva proveniente do Hospício de Brusque. O prontuário se inicia na data de internação no HCS, não constando informações relativas ao período anterior de internação ${ }^{35}$. Solteira, de "cor branca"36, profissão "doméstica", instrução "nula", religião católica. Teve como diagnóstico anotado na folha de ingresso "Esquizofrenia Paranóide". Vera, assim, chegou no HCS com a idade de 47 anos, vinda de outra instituição da qual não se sabe a data de internação. A anotação na folha de "Anamnese" é muito breve, repetindo os dados pessoais sobre procedência, estado civil, grau de instrução. Na folha de Controle de Prescrições Médicas, o diagnóstico anotado é de Parafrenia ${ }^{37}$ e as prescrições entre 1942 e 1946 incluem as tinturas de beladona, valeriana, ópio, boldo e abacateiro, magnésio e medicamentos como Octilan, Bivatol (bismuto), Arsenox, Neosalvarsan, Tiazamida (medicamentos para sífilis e, o último, para quadros infecciosos). Nas anotações da década de 1940, constam os medicamentos e as dosagens, sem maiores informações sobre a interna. Nesse prontuário, é só a partir de 1959 que anotações mais detalhadas são feitas, como esta, de 1959, (dia e mês ilegíveis): "Desorientada parcialmente. Refere-se a alucinações auditivas. [... Ilegível]. Ideias delirantes. Delírios de grandeza e de [prejuízo?]”. Ou esta, de 9/5/1960: “Compareceu para revisão. Estado psíquico inalterado. Trata-se de Esquizofrenia processual”. E de maio de 1963: "Hemiparesia"38, seguido de prescrições de medicamentos, como Adelfan (para pressão alta) e Amplictil (cloropromazina, um dos primeiros psicofármacos introduzidos, indicado para alucinações e delírios) ${ }^{39}$. As prescrições medicamentosas seguem, sem maiores detalhes sobre o estado da paciente, até sua morte, por Acidente Vascular Cerebral aos 73 anos, em outubro de 1968, após 26 anos de internação no HCS. Vera é um dos casos em que o ingresso no asilo e sua posterior transferência para a colônia de alienados resultou no confinamento perpétuo.
35 Os prontuários anteriores à internação no HCS teriam ficado no arquivo morto das instituições de origem, constituindo um acervo a ser ainda pesquisado e analisado.

36 A maioria dos prontuários acessados ou trazia a anotação de cor "branca" ou deixava essa informação sem preenchimento. É preciso acentuar que, mesmo se tratando de uma região de alta incidência de descendentes de imigrantes alemães, italianos e açorianos, Santa Catarina possui um percentual importante de população indígena e negra.

37 Um tipo de esquizofrenia tardia, que associa demência precoce e comportamento paranoide. 0 termo entrou em desuso, mas foi retomado na década de 1950 .

38 Paralisia parcial.

39 Estamos falando da década de 1960. Segundo Borenstein et al. (2007), quando foram introduzidos no HCS, na década de 1950, esses medicamentos tinham um papel coadjuvante dos tratamentos de choque. 


\section{Clara}

Clara ingressou na Colônia em 1953, com 37 anos. Casada, de instrução primária, católica. Quatro filhos vivos, três mortos e dois abortos. Diagnóstico de P.M.D. (Psicose maníaco-depressiva).

Joel Birman (2010) analisa a substituição do diagnóstico de histeria pelo da Psicose Maníaco-Depressiva no Brasil (analisando a documentação do Hospício Nacional dos Alienados), a partir do deslocamento da influência da psiquiatria francesa para a alemã (sobretudo a de Kraepelin) e a adoção de uma perspectiva biologicista para os sintomas antes identificados com a histeria. Se a histeria foi o diagnóstico predominante nas mulheres entre o final do século XIX e o início do XX, a partir desse momento começam a prevalecer os diagnósticos de Psicose Maníaco-Depressiva ${ }^{40}$.

Na pergunta sobre o temperamento antes da doença, aparece como "alegre e trabalhadeira"; e na pergunta sobre conduta com família, amigos, sexo oposto, em casa, no trabalho etc., "muito boa e muito divertida". Até que (anotação em resposta à pergunta sobre "Ato extravagante" - um dos itens do formulário), "começou a só querer sair e um dia atirou-se no mar" (ato que aparece no H.D.A. como tentativa de suicídio). Outra anotação importante é sobre a ausência de relatos de alucinação ou escuta de vozes.

No exame psíquico um dia após a internação, está anotado que "encontra-se em estado de gestação".

Mesmo assim, iniciou o tratamento de eletrochoque quatro dias após a internação, interrompido em função da gravidez. Anotação de 29/7/1953: "A eletroconvulsoterapia foi interrompida devido a estado de gestação". Em 12 de agosto: "Está entrando em fase de depressão novamente" e, em 9 de setembro: "Não melhorou por não poder fazer-se tratamento intensivo devido à gestação". O eletrochoque é retomado em 20 de outubro, com uma anotação sumária nessa data: "Vamos fazer eletrochoque" - chama a atenção a escrita forte e apressada dessa frase, sem maiores explicações, que no contexto da interrupção anterior em função da constatação de gravidez, nos leva a pensar na dramaticidade de uma solução drástica, performatizada na grafia em que a decisão é anotada, tomada apesar da contraindicação por estar grávida.

Já a insulinoterapia (também chamada de coma insulínico), que se iniciou um mês e meio após a internação, foi interrompida em 2 de setembro de 1953, conforme a anotação: "suspensão por estado de gestação", e retomada apenas em 2 de abril de 1954, provavelmente quando já não estava mais grávida. Inicia o tratamento com Cardiazol em março de 1954. O Cardiazol também é uma terapia de choque; quando injetado, é um indutor de convulsão. As sessões com esse medicamento estão anotadas em fichas de eletrochoque, tendo sido a terapia mais utilizada em sua segunda internação, no ano de 1954.

Clara recebeu alta em dezembro de 1953 e foi reinternada em uma data não muito precisa, mas provavelmente março de 1954, com alta definitiva em junho de 1954.

O interesse que esse caso nos despertou está ligado inicialmente à questão da constatação de gestação durante a internação. A paciente chegou grávida no
40 Ver também sobre esse deslocamento, Facchinetti et al., 2008. 
hospital, e isso aparece no exame psiquiátrico inicial. No entanto, recebeu tratamento intensivo com eletrochoque e insulinoterapia, ambos interrompidos em momentos diferentes, em função da gravidez, e posteriormente retomados ainda durante o estado gestacional.

Além disso, é notável a discrepância nas datas de interrupção dos tratamentos do eletrochoque e da insulinoterapia em função da gestação. A insulinoterapia foi iniciada quando já se sabia da gestação; mesmo assim, foi interrompida depois de duas sessões (conforme anotado no prontuário: "Suspensão por estado de gestação"). O eletrochoque durou mais tempo e a interrupção durante a gestação foi curta. A alta e o regresso ao hospital podem estar relacionados ao retorno para casa para o parto, mas essa é apenas uma dedução em função das datas de saída e retorno, não havendo anotações que a confirmem.

A terceira questão é em relação à mudança de temperamento ou conduta da paciente quando adoeceu: de alegre, "trabalhadeira" ${ }^{41}$, divertida, passa a querer sair de casa e tem um episódio de tentativa de suicídio quando já estava grávida. No prontuário, o estado de gravidez modula as idas e vindas dos tratamentos de choque.

\section{Isadora}

Internada aos 20 anos, no ano de 1956, Isadora é descrita como doméstica, branca, instrução primária ("frequentou a escola com algum aproveitamento"), católica, solteira. $\mathrm{O}$ aspecto de interesse de seu prontuário é a importância dada à descrição de sua figura corporal, e ao comportamento e conduta vistos como anormais. No exame somático, é descrita como "biotipo atlético, vestes em desalinho, mucosas ligeiramente descoradas". No exame psíquico: "Agitação psicomotora. Desorientada no tempo e no espaço.” E como Antecedente Mórbido Hereditário: "O avô materno era portador de doença mental". Associada às teorias da degenerescência, a hereditariedade da doença mental como um fator importante na definição do diagnóstico ainda está presente na psiquiatria praticada no HCS nos anos $1950^{42}$.

No H.D.A. (Histórico da Doença Atual) consta a seguinte anotação: "Desde criança com gênio perverso sendo muito castigada pelos pais... Praticou o corte de seu cabelo que era longo"... "Estava triste nesse dia e na ponte, após esperar a prefeitura fechar, cortou as tranças e depois jogou-se no rio para matar-se. Tentou suicídio de outra feita, atirando-se no rio". "Foi noiva duas vezes, desfazendo o noivado por não concordar em ser submissa".

E mais adiante: na resposta à pergunta "como começou a doença?", consta: "Um dia, olhando para o irmão que estava escrevendo, cortou os cabelos e logo após jogou-se na água”.

Novamente, como no caso anteriormente relatado, o que leva à internação é uma tentativa de suicídio (como no caso anterior, também na água), precedida neste caso do olhar sobre o irmão que lê e no ato de cortar os próprios cabelos. Além disso, toda a descrição de seu temperamento e conduta acentua que seria uma "pessoa perversa, má" (segundo os pais), e que não se casou porque não gosta de ser submissa. Ao mesmo tempo, era "muito castigada pelos pais".
41 Há que se notar a diferença entre mulher "trabalhadora" e mulher "trabalhadeira". Enquanto a primeira expressão se refere à mulher que vende sua força de trabalho, a segunda é um adjetivo usado para qualificar a mulher que se dedica ao trabalho, fazendo toda a lida da arrumação e o que mais for demandado ou estiver no horizonte de suas obrigações.

42 Borges e Caponi (2018, p. 1250) veem com surpresa a presença das teorias da hereditariedade mórbida nos relatórios do Serviço de Assistência a Psicopatas do HCS de 1942. A análise dos prontuários dos anos 1950 mostra que essa influência permanece na descrição dos antecedentes do paciente e no estabelecimento dos diagnósticos. 
No acompanhamento de seu tratamento, sua conduta continua sendo objeto de anotação: "Informa estar com amenorreia há dois meses (interrupção da menstruação, o que poderia ser um alerta de gravidez, sendo solteira). E logo em seguida: "Atualmente tem tido conduta extravagante". Não há, no entanto, no prontuário uma descrição mais detalhada do que seria a "conduta extravagante".

Esse é um exemplo de como a dimensão biomédica e científica se articula com modelos morais e socioculturais do que se espera de uma jovem mulher de vinte anos em 1956. No exame somático, as "vestes em desalinho" aparecem ao lado de informações de aspectos fisiológicos (como os "lábios descorados"), indicando que o projeto de psiquiatria científica que vigorava nesse momento se articulava e se fundamentava em questões morais, apresentadas como sintomas. Mesmo capturadas pelo formato frio do formulário, elas estão presentes e se tornam centrais no estabelecimento do diagnóstico.

Vamos ao quarto prontuário.

\section{Conceição}

O prontuário de Conceição indica que foi internada aos 48 anos. De instrução "nula", católica, tendo como informante no momento da internação o marido. É descrita como "calma, deprimida, respondendo às perguntas em idioma alemão". "Fisionomia rígida, lábios voltados para baixo". "Já havia sido internada duas vezes antes, e desta vez a internação foi provocada por uma "nova crise forte", "fala sozinha”. "Tentou suicidar-se" (é o terceiro caso de tentativa de suicídio). "Está na menopausa...”. No exame somático, é constatada a ruptura do períneo, situação ligada ao parto vaginal, que encontramos em outros prontuários analisados. É diagnosticada com PMD/Melancolia. "Tem alucinações auditivas. As vozes dizem que jamais ficará boa". E talvez o dado que mais tenha chamado nossa atenção em todo o prontuário: na resposta ao item "Antecedentes Mórbidos Hereditários", é informado que "tem um filho internado neste hospital". O tratamento básico, como nos demais casos descritos, é o eletrochoque.

É recorrente nos prontuários as mulheres sendo encaminhadas pelo marido ou pelo pai, no caso de solteiras, e estes são também o "informante" dos funcionários que preenchem o formulário no Livro de Registro, sendo que essas informações iniciais também constarão nos prontuários.

No caso de Conceição, o fato de ter um filho internado provoca em quem lê o prontuário um deslocamento do foco dos sintomas narrados para uma situação familiar dramática e nos faz dar um passo atrás no fio linear da narrativa sobre a trajetória de adoecimento e internação da paciente.

\section{Algumas conclusões}

Os prontuários do hospital seguem um roteiro formal de perguntas e itens a serem preenchidos, tabelas de aplicação de tratamentos, exames clínicos divididos em somáticos e psíquicos, respostas aos tratamentos. Algumas anotações são extremamente sintéticas, outras se estendem. Marido e pai são os "informantes" recorrentes, os que produzem a narrativa inicial que acompanha o processo de 
internação e será também inscrita nas partes descritivas do prontuário. De tudo o que é narrado, há escolhas por parte de quem anota as informações, algumas são descartadas, outras se tornam relevantes a partir do momento em que ganham registro no documento individual que traz as informações daquela pessoa dentro do hospital. É nesse documento que o médico anota suas observações, diagnósticos, prescrições, é ele que outros médicos consultam para fazer o acompanhamento e novas prescrições, ou em que outros profissionais anotam os controles e aplicações das terapêuticas prescritas.

O prontuário é um objeto mediador dos procedimentos e práticas médicas e das micropolíticas da relação terapêutica. Nota-se uma especial atenção e controle das questões ligadas à vida reprodutiva das mulheres: menstruação, gestação, menopausa, abortos, número de filhos. Se, nas informações dos pacientes homens, pergunta-se sobre a vida sexual, no caso das mulheres o que é relevante para a instituição é o ciclo reprodutivo. Mas a preocupação com a conduta sexual das mulheres não está de modo algum ausente, senão nas perguntas do prontuário, ela aparece nas descrições do acompanhamento de suas reações ao tratamento, comportamento dentro do hospital etc. ${ }^{43}$. Os tratamentos são, na maior parte dos casos analisados referentes à década de 1950, de choque físico (elétrico) ou químico (insulina ou cardiazol), mesmo com a introdução do psicofármaco cloropromazina.

O período dos prontuários analisados pode ser definido como um momento não só de transição, mas também de justaposição em diversos aspectos. No modo de gestão, transita-se entre um modo de assistência psiquiátrica filantrópica e asilar, realizada pelas instituições anteriores, uma delas também administrada pelas irmãs da Divina Providência, e o projeto de modernização da assistência psiquiátrica. Nas técnicas diagnósticas e terapêuticas, na transição entre saberes informados pelas teorias raciais e da degeneração (que aparecerão nas informações antropométricas do prontuário) e pelos tratamentos com ervas e tinturas, e as novas técnicas dadas pela biologização da doença mental, através da inclusão de novos tratamentos de choque além do eletrochoque, já praticado nos anos 1940. No entanto, mesmo nesse período posterior, as teorias da degenerescência e da hereditariedade mórbida permanecem ${ }^{44}$.

Se por um lado, os prontuários falam muito mais da instituição e da "ciência psiquiátrica" daquele momento, eles também mostram as dimensões morais presentes nas anotações médicas, assim como, de modo oblíquo e marginal, informações fragmentárias sobre a vida daquelas mulheres. O que estamos tentando ler são pistas, perguntas, dúvidas, lacunas e silêncios: a mãe que é internada onde está o filho, a jovem que desfez noivado duas vezes por não querer ser submissa e que, após observar o irmão escrevendo, corta os cabelos e se joga no rio, a mulher grávida que começa a querer sair de casa e acaba se jogando no mar. Vestígios brutos de "vidas que não pediam absolutamente para ser contadas dessa maneira", tal como observa Farge (2017, p. 13) em relação ao arquivo judiciário francês do século XVIII. Em algum momento da leitura dos prontuários, começamos a tentar esboçar os rostos dessas mulheres, compor narrativas, que podem até ser
43 Fontoura (1997) identifica, na leitura dos prontuários de internos no HCS no ano de 1942, uma recorrência de fatores que ocasionaram as internações. No caso dos homens, "alcoolismo, vadiagem, desordem..." (p. 76); no caso das mulheres, aparecem nos prontuários "misticismo, condutas sexuais inadequadas, perda de afeto". Entre as condutas sexuais inadequadas, incluem-se as relações sexuais antes do casamento, a ruptura de noivado ou a recusa em se casar. Para Bertolli Filho (1996), apesar do caráter "marcadamente técnico dos prontuários", eles tendem a "derivar para observações como a sensibilidade social dominante no período" (p. 176), como, ao se referir a doenças venéreas como ligadas a depravações, vagabundagens; ou emitir julgamentos estéticos sobre os pacientes, como aparência física e modo de se vestir.

44 Não encontramos nos prontuários analisados referentes aos anos 1950 menções a psicocirurgias, como a lobotomia, uma das novas técnicas preconizadas pela psiquiatria científica e colocada em prática no período na Colônia Juliano Moreira, no Rio de Janeiro (Venâncio, 2011). 
fabulares, mas talvez não mais do que aquela composta pela incisão tanto técnica quanto moral da leitura psiquiátrica dos sintomas e sua nosologia.

Em um momento posterior da pesquisa, pretendemos cruzar os dados dos prontuários com outros documentos, como os Livros de Ocorrência e relatórios de gestão do período. Talvez ali haja algum registro sobre a "atitude extravagante" de Isadora, mencionada no prontuário ou sobre a saída temporária de Clara, até a nova internação ${ }^{45}$. Buscar essas pistas e conexões, perdidas, mais do que preencher lapsos ou espaços em branco dos prontuários, é uma tentativa de recontar outra história do manicômio, outras histórias, para além da disciplina, do controle e das violências institucionais. Os vestígios encontrados nos documentos do arquivo psiquiátrico, lidos como fragmentos etnográficos, nos ajudam a imaginar as vidas dessas mulheres que passaram pela Colônia Santana ou por lá ficaram e fazer com que deixem de ser apenas resíduos da história da instituição.
45 Assim como outros prontuários que, por questão de espaço, não entraram neste artigo, como o de Rosa, que pedia para voltar para casa e telegrafava para a família durante suas sucessivas internações.

Recebido: 07/11/2019

Aprovado: 24/03/2020 
Sônia Weidner Maluf, Mirella Alves de Britto, Inaê label Barbosa e Camila Andressa Dias da Silva

\section{Referências}

ABÉLÈS, Marc. État. In: BONTE, Pierre; IZARD, Michel (Dir.). Dictionaire de l'ethnologie et de l'anthropologie. Paris: PUF, 1992. p. 239-242.

BARROS, Oscar Monteiro de. Recentes progressos no domínio das moléstias infeciosas. Revista de Medicina, USP, abril, p. 7-18, 1942.

BASAGLIA, Franco. A instituição negada. Rio de Janeiro: Graal, 1985 [1968].

BERTOLLI FILHO, Claudio. Prontuários médicos: fonte para o estudo da história social da medicina e da enfermidade. História, Ciências, Saúde - Manguinhos, Rio de Janeiro, v. 3, n. 1, p. 173-180, 1996.

BIEHL, João. Vita: life in a zone of social abandonment. Photographs by Torben Eskerod. Berkeley: University of California Press, 2005.

BIRMAN, Joel. A cena constituinte da psicose maníaco-depressiva no Brasil. História, Ciências, Saúde - Manguinhos, Rio de Janeiro, v. 17, supl. 2, p. 345-371, dez. 2010.

BORENSTEIN, Miriam Süsskind et al. Historicizando a enfermagem e os pacientes em um Hospital Psiquiátrico. Revista Brasileira de Enfermagem, v. 56, n. 2, p. 201-205, mar.abr. 2003.

BORENSTEIN, Miriam Süsskind et al. Terapias utilizadas no Hospital Colônia Sant 'Ana: berço da psiquiatria catarinense (1941-1960). Revista Brasileira de Enfermagem, v. 60, n. 6, p. 665-669, nov.-dez. 2007.

BORGES, Viviane Trindade; CAPONI, Sandra. A assistência psiquiátrica a crianças anormais no Hospital Colônia Sant 'Ana (Santa Catarina, Brasil, 1940). História, Ciências, Saúde - Manguinhos, Rio de Janeiro, v. 25, n. 4, p. 1239-1259, out.-dez. 2018.

BORGES, Viviane. Arquivos marginais: outras fontes, outros acervos. Revista Eletrônica Ventilando Acervos, Florianópolis, v. 4, n. 1, p. 97-108, dez. 2016.

BORGES, Viviane. Um "depósito de gente": as marcas do sofrimento e as transformações no antigo Hospital Colônia Sant’Ana e na assistência psiquiátrica em Santa Catarina, 1970-1996. História, Ciências, Saúde - Manguinhos, Rio de Janeiro, v. 20, n. 4, p. 15311549, out.-dez. 2013.

BUTLER, Judith. Precarious life. London: Verso, 2004.

CAMPOS, Paulo Fernando de Souza. Os enfermos da razão: cidade planejada, exclusão e doença mental (Maringá, 1960-1980). São Paulo: Annablume; FAPESP, 2004.

CARRARA, Sérgio. Crime e loucura: o aparecimento do manicômio judiciário na passagem do século. Rio de Janeiro: EdUERJ; São Paulo: EdUSP, 1998.

CASTEL, Robert. L'ordre psychatrique: l'âge d'or de l'alienisme. Paris: Les Éditions de Minuit, 1977.

COOPER, David. Psiquiatria e antipsiquiatria. São Paulo: Perspectiva, 1982 [1967].

COOPER, David; LAING, Ronald David. Razão e violência. Rio de Janeiro: Vozes, 1982 [1964].

COSTA, Eliani. Hospital Colônia Sant'Ana: o saber/poder dos enfermeiros e as transformações históricas (1971-1981). 299 f. Tese (Doutorado em Enfermagem) - Universidade Federal de Santa Catarina, Florianópolis, 2010.

CUNHA, Maria Clementina Pereira. O espelho do mundo: Juquery, a história de um asilo. Rio de Janeiro: Paz e Terra, 1986.

CUNHA, Olivia Maria G. Tempo imperfeito: uma etnografia do arquivo. Revista Mana, 
Sônia Weidner Maluf, Mirella Alves de Britto, Inaê label Barbosa e Camila Andressa Dias da Silva

2004.

DELEUZE, Gilles. Foucault. São Paulo: Brasiliense, 1988.

ENGEL, Magali Gouveia. Os delírios da razão: médicos, loucos e hospícios (Rio de Janeiro, 1830-1930). Rio de Janeiro: Fiocruz, 2001. (Coleção Civilização e Loucura).

FACCHINETTI, Cristiana et al. No labirinto das fontes do Hospício Nacional de Alienados. História, Ciências, Saúde - Manguinhos, Rio de Janeiro, v. 17, supl. 2, p. 733-768, dez. 2010.

FACCHINETTI, Cristiana; RIBEIRO, Andréa; MUÑOZ, Pedro F. de. As insanas do Hospício Nacional de Alienados. História, Ciências, Saúde - Manguinhos, Rio de Janeiro, v. 15, supl., p. 231-242, jun. 2008.

FARGE, Arlette. O sabor do arquivo. São Paulo: Edusp, 2017.

FONTOURA, Arselle de Andrade da. Por entre luzes e sombras... Hospital Colônia Santana: (re)significando um espaço da loucura. Dissertação (Doutorado em História) - Universidade Federal de Santa Catarina, Florianópolis, 1997.

FOUCAULT, Michael. História da loucura. São Paulo: Perspectiva, 1978.

FOUCAULT, Michel. Archéologie du savoir. Paris: Gallimard, 1969.

FOUCAULT, Michel. O poder psiquiátrico. São Paulo: Martins Fontes, 2006.

FOUCAULT, Michel. Sobre a história da sexualidade. In: MACHADO, Roberto. Microfísica do poder. Rio de Janeiro: Graal, 1979 [1977]. p. 243-276.

GERBER, Rose Mary. Mulheres e o mar: uma etnografia sobre pescadoras embarcadas na pesca artesanal no litoral de Santa Catarina, Brasil. Tese (Doutorado em Antropologia Social) - Universidade Federal de Santa Catarina, 2013.

GIUMBELLI, Emerson. Para além do "Trabalho de Campo": reflexões supostamente malinowskianas. Revista Brasileira de Ciências Sociais, v. 17, n. 48, p. 91-107, fev. 2002.

GOFFMAN, Ervin. Manicômios, prisões e conventos. São Paulo: Perspectiva, 1998 [1961].

GOMES, Allan Hentique et al. A loucura na cidade de Joinville no século XX: o paradigma indiciário como proposta metodológica de pesquisa em psicologia. Confluências culturais, v. 5, n. 1, p. 81-95, 2016.

GUATTARI, Félix; ROLNIK, Suely. Micropolítica: cartografias do desejo. 7. ed. Petrópolis: Vozes, 2005.

LAING, Ronald David. O eu dividido: estudo existencial da sanidade e da loucura. Petrópolis: Vozes, 1987.

LOWENKRON, Laura; FERREIRA, Letícia. Anthropological perspectives on documents: ethnographic dialogues on the trail of police papers. Vibrant - Virtual Brazilian Anthropology, Brasília, v. 11, n. 2, p. 76-112, 2014.

MACHADO, Roberto et al. Danação da norma. Rio de Janeiro: Graal, 1978.

MALUF, Sônia. Mitos coletivos, narrativas pessoais: cura ritual, trabalho terapêtico e emergência do sujeito nas culturas da "Nova Era". Mana, v. 11, n. 2, p. 499-528, 2005.

MELO, Marcos Costa. História da psiquiatria: da ideia à materialização - a relação Estado-Colônia Santana. Psychiatry on line Brasil, v. 5, n. 12, 2000.

PIGEAUD, Jackie. Le style d'Hippocrate ou l'écriture fondatrice de la médecine. In: DETIENNE, Marcel (Org.). Les savoirs de l'écriture en Grèce ancienne. Lille: Presses Universitaires de Lille, 1988. p. 305-329.

PORTOCARRERO, Vera. Arquivos da loucura: Juliano Moreira e a descontinuidade histó- 
Sônia Weidner Maluf, Mirella Alves de Britto, Inaê label Barbosa e Camila Andressa Dias da Silva

rica da psiquiatria. Rio de Janeiro: Fiocruz, 2002.

RILES, Annelise. Introduction: in Response. In: Documents: artifacts of modern knowledge. Ann Arbor, Michigan: University of Michigan Press, 2006. p. 1-37.

SCOTTI, Zelinda Rosa. Os prontuários do Hospício São Pedro: metodologia para formação de banco de dados. Revista Ágora, Vitória, n. 12, p. 1-12, 2011.

TEIXEIRA, Mario. Hospício e poder. Brasília: Ministério da Saúde, 1993.

THIAUDIÈRE, Claude. Les usages médicaux de l'écrit: prescription et institution de la maladie. In: COTON, Christel; PROTEAU, Laurence (Dir.) Les paradoxes de l' écriture: sociologie des écrits professionnels dans les institutions d'encadrement. Rennes: Presses Universitaires de Rennes, 2012.

VEN NCIO, Ana Teresa A.; POTENGY, Gisélia. O asilo e a cidade: histórias da Colônia Juliano Moreira. Rio de Janeiro: Garamond, 2015.

VEN NCIO, Ana Teresa. Da colônia agrícola ao hospital-colônia: configurações para a assistência psiquiátrica no Brasil na primeira metade do século XX. História, Ciências, Saúde - Manguinhos, Rio de Janeiro, v. 18, supl. 1, p. 35-52, dez. 2011.

VIANA, Bruna da Silveira. Entre discursos e práticas: menores e loucura no Hospital Colônia Sant’Ana (1942-1944). 2013. 62 f. Monografia (Graduação em História) - Universidade do Estado de Santa Catarina (UDESC), Florianópolis, 2013.

VIANA, Bruna da Silveira. Salvaguarda e possibilidades de pesquisa: os prontuários do antigo Hospital Colônia Santana. I Simpósio de Patrimônio Cultural de Santa Catarina - “Patrimônio Cultural: Saberes e Fazeres Partilhados”, Florianópolis, 21-22 nov. 2013.

VIANA, Bruna da Silveira. Um lugar para os ditos anormais: assistência psiquiátrica a crianças e jovens na primeira década do Hospital Colônia Sant’Ana (1942-1951). Dissertação (Mestrado em História) - Universidade do Estado de Santa Catarina (UDESC), Florianópolis, 2015.

WADI, Yonissa Marmit. “Entre muros”: os loucos contam o hospício. Topoi, v. 12, n. 22, p. 250-269, jan.-jun. 2011.

WADI, Yonissa Marmit. A história de Pierina: subjetividade, crime e loucura. Uberlândia: EDUFU, 2009a.

WADI, Yonissa Marmit. Uma história da loucura no Tempo Presente: os caminhos da assistência e da reforma psiquiátrica no Estado do Paraná. Tempo e Argumento, Florianópolis, v. 1, n. 1, p. 68-98, jan.-jun., 2009b. 